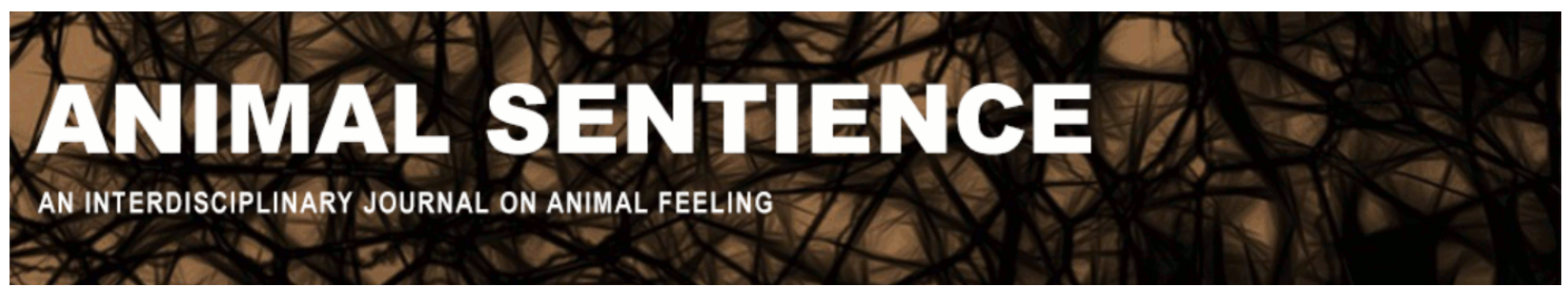

Bookstein, Fred L. (2016) "Beyond words," yes, but also beyond numbers. Animal Sentience 2(2)

DOI: $10.51291 / 2377-7478.1126$

Date of submission: 2016-07-18

Date of acceptance: 2016-07-20

(c)

This article has appeared in the journal Animal

Sentience, a peer-reviewed journal on animal

cognition and feeling. It has been made open access,

free for all, by WellBeing International and deposited

in the WBI Studies Repository. For more information,

please contact

wbisr-info@wellbeingintl.org.

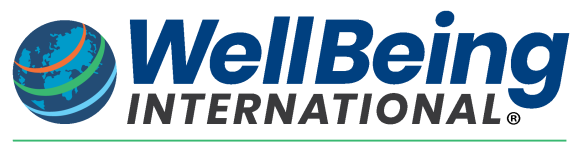

SOLUTIONS FOR PEOPLE, ANIMALS AND ENVIRONMENT 


\title{
"Beyond words," yes, but also beyond numbers
}

\author{
Commentary on Safina on Animals Feel
}

\author{
Fred L. Bookstein \\ Department of Statistics, University of Washington
}

\begin{abstract}
Safina's fascinating series of fifty separate feuilletons tries to bridge a painful Methodenstreit in contemporary ethology mainly by an accumulation of anecdotes. Some deal with his own dogs, but most derive from reading or conversing with observers of a wider range of social mammals including elephants, wolves, apes, and whales. In spite of the many interruptions by travesties of the academic lifestyle and its literature, there is a point to be made, concerning the centrality of evidence about cooperative behavior styles, especially aspects of child-rearing, for the understanding of "what animals think and feel." But Safina's argument would be a lot more persuasive, at least to this outsider, if he were more aware of his own methodological preferences and the restraints they impose on the rhetoric of scientific persuasion. In spite of my skepticism, I sketch a possible application of his ideas to human neuroteratology.
\end{abstract}

Fred L. Bookstein is Professor Emeritus of Statistics at University of Washington and retired Professor of Life Sciences, University of Vienna. His research is on the foundations of scientific inference, especially in the sciences of complex organized systems such as living creatures (Measuring and Reasoning, 2014). http://www.anthropology.at/people/facul ty-and-staff/fred-bookstein

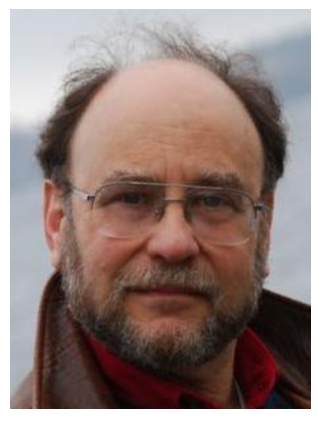

"Science is confirming the obvious..."

Safina, 2015:23

"For the animal shall not be measured by man" Henry Beston, 1928

(as quoted by Safina, 2015:x)

The most important word in this book is the little logical trope "obvious" (or, adverbially, "obviously"). It occurs 31 times here, of which the instance in my epigraph is the first: "Science is confirming the obvious: other animals hear, see, and smell with their ears, eyes, and noses; are frightened when they have reason for fright and feel happy when they appear happy" (Safina, 2015, page 23). Here are some of the others: “It is obvious ... that elephants don't have romantic love" (page 29). "Obviously, the dog wants to go out" (page 30). "Wolves, apes, elephants, whales - obviously bright" (page 192). [That dogs understand the existence of other 
minds] is "happening all around us, twenty-four/seven, blindingly obvious" (page 249). "Obviously many, many animals know the difference between themselves and the rest of the world" (page 276, in the course of a lampoon of the Gallup mirror test). [But note that the methodology I am invoking here, the censusing of a verbal behavior, is one that Safina himself firmly deprecates.]

So if there is a scientific methodology for "confirming the obvious," well, what kind of methodology might it be? The closest I can come to it from inside the standard canon is the approach that Peirce (1934) named "abduction" (in contemporary artificial intelligence it is called "inference to the best explanation"). As he characterized it in 1903,

- The surprising fact, $C$, is observed;

- But if $A$ were true, $C$ would be a matter of course,

- Hence, there is reason to suspect that $A$ is true.

For a multitude of instances of this specific logical tactic, see Bookstein (2014).

What could such a dependence mean in a context of interspecies understanding? Safina notes, as early as page 25 , that "all the evidence indicates widespread consciousness." But obviously [sic] any such assertion must be based on a specific construal of the word "evidence," a construal that might not be shared with other branches of the science (broadly, evolutionary psychology) to which Safina is most closely affiliated. What counts as evidence? Is it only what counts, i.e., numbers and their statistics?

Apparently not, as the bulk of this book is a retelling of anecdotes, separate stories of the behaviors observed in individual animals at individual moments over the history of our observations of them. Hardly any of these purported behavioral trends can be confirmed in experiments with controlled stimuli: that is, they cannot be counted. For Safina is not particularly interested in reproducibility. As he admits after one particularly evocative story, "one dolphin sought and accepted help, one didn't" (page 369). The animals involved are mainly (though not exclusively) mammals, more precisely the social mammals, those characterized by cooperative hunting and rearing and, typically, by fission-fusion community structures that require keeping track of a lot of distinct individuals. In the background lurk some solid principles of evolutionary neurology. The brains of the species under discussion here - elephants, wolves, apes, orca - are overwhelmingly more similar to ours than they are different; ergo, their modes of function can be expected to overlap; ergo, when we see in an animal a behavior that resembles a human behavior that we know to be a manifestation of conscious thinking or feeling, there is no good reason to reject the analogous claim as a proximal explanation of the analogous animal behavior.

Not so fast, please. From a hypothesis (Peirce's "there is reason to suspect") to an assertion of fact is quite a leap. Here is a typical example, from page 247 :

"The swan just showed that he understood that he needed to avoid the dogs and that he 
understood the limitations of their movement in water. He understands how to use the water to stay completely safe while holding himself so close that, were he on land, the dogs could cover the distance in two bounds, requiring perhaps half a second. The swan demonstrated theory of mind and mastery of medium."

"Not proven," as the Scots would say. To treat this observation (which is, after all, an anecdote, not claimed to be any sort of repeatable result) as a demonstration of "understanding" is simply to beg the question I've been probing throughout this commentary. If it is not treated as "obvious," is there, in fact, any reason to treat this use of the word "understand" as true? Nowhere in this book, notwithstanding the range of mockeries of evolutionary psychology in Part III, "Whines and Pet Peeves," can I find any discussion of this crucial logical hinge. One cannot circumvent the "Hard Problem" of consciousness (its inherence in biologically organized matter) just by privileging one of its domains, the verbal: likewise for Safina's theory of animal minds, which privileges the social. On page 29 we are informed that "in science, the simplest interpretation of evidence is often the best," but to presume that this "simplicity" is a matter of the individual cognitive faculty rather than the Denkkollektiv is a deep misunderstanding of everything we know about the social structure of science today. And Safina's book is squarely set within that same social structure: he is, after all, the inaugural Professor of Nature and Humanity at Stony Brook University.

A biologist like me finds it hard to imagine a current book by a professor of natural sciences that includes not a single figure, not a single table. To appreciate a table is perhaps a modern human artifact, but to appreciate a figure need not be (even according to Safina himself, who quotes an account of dolphins looking at drawings of dolphins). It would be well, then, to search the domain of human psychology for the traces of subdisciplines that likewise eschew graphical aids. And one comes obviously to mind, the one founded by Freud (who comes off pretty well in Safina's pages): depth psychology and, more generally, abnormal human psychology.

Indeed the claims of clinical psychology are often conveyed in stories, not tables. In Ann Streissguth's (1997) magisterial summary of the clinical facies of fetal alcohol syndrome, the core of the exposition is the "vignettes," the individual case studies. The most widely read popular exposition about this disease, Michael Dorris's (1989) bestseller The Broken Cord, summarizes the situation of his fetal-alcohol-affected son:

"My son will forever travel through a moonless night with only the roar of wind for company. Don't talk to him of mountains, of tropical beaches. Don't ask him to swoon at sunrises or marvel at the filter of light through leaves. He's never had time for such things, and he does not believe in them. He may pass by them close enough to touch on either side, but his hands are stretched forward, grasping for balance instead of pleasure. He doesn't wonder where he came from, where he's going. He doesn't ask who he is, or why. Questions are a luxury, the province of those at a distance from the periodic shock of rain. Gravity presses Adam so hard against reality that he doesn't feel the points at which he touches it. A drowning man is not separated from the lust for air by a bridge of thought - he is one with it - and my son, conceived and grown in an 
ethanol bath, lives each day in the act of drowning. For him there is no shore." (page 264)

In terms of human studies of fetal alcohol syndrome, Dorris's kind of argument wins the battle hands-down. Descriptions of the syndrome by averages or correlations of psychological test scores support neither effective diagnosis nor effective understanding, and the best methods for detecting the actual brain damage done by prenatal alcohol (for an overview, see NCBDDD, 2004), which are image-based, do not align with the reasons that we actually care about this particular epigenetic syndrome, namely, its devastating effects on adult life in a modern Western society (Streissguth et al., 2004). Their poetic diction aside, Safina's stories in Beyond Words are set in this same rhetoric: depth-psychological, not scientific, narrative. We are told about the mental state of another, or rather, an Other, to which we are bound by a tie that is in Dorris's case social (his son was adopted) but, for Safina, the tie is evolutionary: we are all mammals together.

This originally sociological method of Verstehen, understanding the Other through empathy, lies at the core of the contemporary humanities. It is indeed a style of persuasion. To what extent it overlaps with the objectifying, reductionist methods of contemporary science, if it overlaps at all, is an arena of energetic intellectual contention just now. Rather, in directing our attention to the overlap of animal consciousness with our own, it speaks to the general theme that "in wildness is the preservation of the world," a heightened regret for the depredations of human overpopulation on the freedom of these animals to continue as what they were before the evolution of Homo sapiens. The tradition to which this book most belongs is indeed the literature of conservation, not ethology. Its closest current companion is probably Wilson's (2016) call for preservation of prehuman ecologies in general.

Then to ask whether Safina's rich and rewarding volume is ethology, or biology, or science at all, is not a fruitful line of commentary. Where he refers to numbers (animal demographics, titres of testosterone), it is dry and desiccated. But where it recounts stories, it becomes powerful in the same way that fiction and myth become powerful. The power of this prose derives from our ability, as human readers, to see ourselves in the situation being described. Indeed, to see ourselves in two roles at the same time: the elephant matriarch (for example) and also the ethologist observing her.

Like any other academic, Safina is aware of this antinomy. As he says, on page 365,

"Me, I am most skeptical of those things I'd most like to believe, precisely because I'd like to believe them. Wanting to believe something can skew one's view."

This is the dilemma of his readers as well. When he says, as on page 244, "Your dog really does love you....Your dog genuinely loves you," what is the role of the adverbs "really" and "genuinely"? Surely they are not statements about the dog; they are statements about Safina's own beliefs. Was the text intended to persuade a skeptic, or only to make the reader who already credits such a proposition feel better? I suspect the latter is the case. Knowing that you 
want to believe something (in this setting, the claims of animal thinking and feeling, like reading about how desperately elephants or orca protect their "babies" - and note the emotional dominance of that word over a more neutral alternative like "offspring") ought to reset the reader's persiflage detector to a very sensitive threshold. This is a commonplace of scientific inference nowadays, especially in the physical sciences (in Freeman Dyson's (2004, page 258) trenchant bon mot, "the professional duty of a scientist confronted with a new and exciting theory is to try to prove it wrong"). The principle does not match Safina's stance too well.

Safina musters a great mass of evidence about what is "obvious" in the contemporary ethology of mental processes. That he never pauses to examine what he himself might mean by a slogan like "Science has confirmed the obvious" is not necessarily a drawback from the point of view of his intended readership. Yes, it might interfere with the dissemination of his ideas into the academic sector in which he presently lives. But his own words indicate his near-total disdain for the intellectual styles that are currently fashionable in that sector. We may not be able to ascertain the disciplinary impact of this book for decades. Meanwhile, it is worth cherishing for its narrative energy and the elegance of its language. Beyond Words was designed not to convince you of anything, but rather to make you think and imagine. In that purpose, I believe it succeeds splendidly.

Acknowledgement. These comments derive partly from my presentation "Limits of 'the scientific method' in nearly normal brains" at the Third Vienna Conference on Consciousness, November 6-7, 2015, with support from the Faculty of Biological Sciences of the University of Vienna.

\section{References}

Bookstein, F. L. (2014) Measuring and Reasoning: Numerical Inference in the Sciences. Cambridge University Press.

Dorris, M. A. (1989) The Broken Cord: Fetal Alcohol Syndrome and the Loss of the Future. Harper.

Dyson, F. (2004) Infinite in All Directions. Harper.

NCBDDD (National Center for Birth Defects and Developmental Disabilities). (2004) Fetal Alcohol Syndrome: Guidelines for Referral and Diagnosis.

Peirce, C. S. (1934) Pragmatism and abduction: Lecture VII. (Lectures given at Harvard University, March 26 to May 17, 1903). Collected Papers of Charles Sanders Peirce, Volume V: Pragmatism and Pragmaticism. Cambridge: Belknap Press of Harvard University Press.

Safina, C. (2015) Beyond Words: What Animals Think and Feel. New York: Holt.

Safina, C. (2016) Animals think and feel: Précis of Beyond words: What animals think and feel (Safina 2015). Animal Sentience 2016.002 
Streissguth, A. P. (1997) Fetal Alcohol Syndrome: A Guide for Families and Communities. Paul A. Brookes.

Streissguth, A. P., Bookstein, F. L., Barr, H. M., Sampson, P. D. and Young, J. K. (2004) Risk factors for adverse life outcomes in fetal alcohol syndrome and fetal alcohol effects. Journal of Developmental and Behavioral Pediatrics 25:228-238.

Wilson, E. O. (2016) Half-Earth: Our Planet's Fight for Life. Liveright. 